\title{
Clinical outcomes and utility of cardiac catheterization prior to superior cavopulmonary anastomosis
}

David W. Brown, MD

Kimberlee Gauvreau, $S c D^{a}$

Adrian M. Moran, $\mathrm{MD}^{\mathrm{a}}$

Kathy J. Jenkins, MD, MPH

Stanton B. Perry, MD

Pedro J. del Nido, MD ${ }^{b}$

Steven D. Colan, $\mathrm{MD}^{\mathrm{a}}$

From the Department of Cardiology ${ }^{\mathrm{a}}$ and Department of Cardiac Surgery, ${ }^{\mathrm{b}}$ Children's Hospital, Boston, Mass.

Received for publication June 10, 2002; revisions requested Aug 26, 2002; revisions received Oct 25, 2002; accepted for publication Nov 1, 2002

Address for reprints: David W. Brown, MD, Department of Cardiology, Children's Hospital, 300 Longwood Ave, Boston, MA 02115 (E-mail: david.brown@cardio. chboston.org).

J Thorac Cardiovasc Surg 2003;126:272-81

Copyright $\odot 2003$ by The American Association for Thoracic Surgery

$0022-5223 / 2003 \$ 30.00+0$

doi:10.1016/S0022-5223(03)00054-0
Objectives: We sought to characterize the outcomes of routine catheterization prior to superior cavopulmonary anastomosis and to determine if some patients were unlikely to benefit from catheterization and thus might be evaluated preoperatively with noninvasive methods alone.

Background: Congenital heart disease patients with single ventricle physiology undergo routine echocardiography and cardiac catheterization prior to superior cavopulmonary anastomosis to determine anatomic and hemodynamic suitability for this procedure.

Methods: We performed a retrospective review of all infants $(\mathrm{n}=114)$ evaluated for potential superior cavopulmonary anastomosis at our institution from January 1997 to June 2000 .

Results: Patients' median age was 5.5 months. Full echocardiograms were obtained in 79 patients $(69 \%)$. At catheterization a total of 41 interventions were performed in 35 patients $(31 \%)$. Twenty-seven patients $(24 \%)$ were transfused, 18 patients (17\%) required cardiac intensive care unit admission, and median length of stay following catheterization was 1 day (range 0 to 22). Complications occurred in 28 patients $(25 \%)$, most transient. Of 51 patients who had complete echocardiograms without indication for catheterization, none subsequently had significant interventions and only 2 had new findings at catheterization. Three candidates were excluded from operation; all 111 others underwent successful procedures and survived to hospital discharge.

Conclusions: Interventions were frequent at catheterization prior to superior cavopulmonary anastomosis, but transient complications, transfusion, intensive care unit admission, and prolonged hospital length of stay were common. For patients in whom no issues indicating need for catheterization are identified by echocardiogram, routine catheterization rarely results in new information or intervention. These patients may be more safely evaluated preoperatively using exclusively noninvasive techniques.

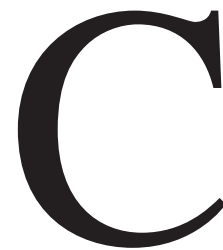

urrent clinical practice for pediatric patients undergoing staged palliation of functional single ventricle includes echocardiographic (ECHO) evaluation as well as routine cardiac catheterization (CATH) prior to superior cavopulmonary anastamosis (SCPA), also known as bidirectional Glenn operation. Few published data exist on the clinical utility of information obtained from pre-SCPA ECHO and CATH evaluation. We sought to characterize the quality of the infor- 
mation obtained by ECHO and $\mathrm{CATH}$; the interventions performed at $\mathrm{CATH}$; related outcomes including fluoroscopy time, frequency of transfusion, intensive care unit (ICU) admission, and hospital length of stay (LOS); as well as the nature and extent of CATH complications. Finally, we sought to determine whether a group might be identified who were unlikely to benefit from CATH in terms of either intervention or new diagnoses that might influence the surgical management.

\section{Methods}

We reviewed the records of patients at our institution with single ventricle physiology who were evaluated with ECHO and CATH prior to SCPA during the 3-year period from January 1997 through June 2000. Patients were identified by a search of the cardiology and cardiac surgery databases.

Patients were excluded if their ECHO, CATH, or surgical information was missing or unavailable. To minimize bias related to institutional practice, patients were also excluded if either the pre-SCPA ECHO ( 2 patients) or pre-SCPA CATH (6 patients) was performed at a nonaffiliated hospital.

In addition to demographic information collected at the time of $\mathrm{CATH}$, medical records were reviewed for any prior diagnoses, ECHOs, CATHs, and operative procedures. Ventricular type was assigned based upon previously published criteria. ${ }^{1}$

For this study, the pre-SCPA ECHO data were obtained from the official report of the staff echocardiographer who interpreted the study without secondary review. For those with multiple ECHOs, the study in closest temporal proximity prior to the pre-SCPA CATH was selected as the pre-SCPA study. As is usual in clinical practice, congenital anatomic diagnoses (ie, the presence or absence of bilateral superior vena cavae) based on prior investigations or surgical observations were recorded and included in the body of known facts at the time of pre-SCPA CATH.

Complete ECHOs were defined as those including assessments of ventricular function, atrioventricular valve regurgitation, atrial septum, aortic arch obstruction (both ascending and descending), proximal branch pulmonary arteries, and pulmonary venous pathways. Distal arch obstruction, especially for those after aortic arch reconstruction, was defined by Doppler flow velocities greater than $3 \mathrm{~m} / \mathrm{s}$ in association with a greater than $50 \%$ reduction in lumen diameter. Adequate imaging of the right pulmonary artery was considered visualization to its passage behind the superior vena cava; adequate imaging of the left pulmonary artery was considered visualization of 3 or more lumen diameters distal to its origin. For this study, both the ECHO and CATH designations of mild, moderate, or severe pulmonary artery (PA) stenosis were based upon a visual estimate for stenosis in the context of the size of the adjacent segment of unnarrowed pulmonary artery, with a mild stenosis representing $\sim 25 \%$ narrowing, moderate stenosis $\sim 50 \%$ narrowing, and severe stenosis $\sim 75 \%$ narrowing. The standard of ventricular function used was a visual estimate of the ejection fraction; mild dysfunction was an ejection fraction $\sim 50 \%$, moderate dysfunction $\sim 40 \%$, and severe dysfunction $\sim 30 \%$ or less. Atrioventricular valve regurgitation assessment was based upon the width of the proximal regurgitation jet by color Doppler relative to the size of the patient. Any limitations of the pre-SCPA study, such as failed sedation or poor ECHO windows, were recorded.

Pre-SCPA CATH data were taken from the official report of the staff catheterizing cardiologist who interpreted the study, without secondary review. For patients with more than $1 \mathrm{CATH}$, the procedure immediately preceding SCPA was considered the preSCPA CATH. In addition to hemodynamic data and calculations, angiographic data and interventions were recorded. CATH, postCATH recovery, and hospital records were reviewed for fluoroscopy time, blood product transfusions given, whether patients had ICU admission, any other complications, and hospital LOS. For those who remained in the hospital until their operation, the CATH LOS was considered over on the day of the operation, as SCPA is typically a same-day admission surgery at our institution. Complications were recorded and included arrhythmias (those requiring treatment or significant enough to be listed in final CATH report), acidosis (arterial $\mathrm{pH}<7.25$ ), nonelective intubation, initiation of intravenous inotropes in the CATH lab, chest compressions, as well as other miscellaneous complications.

For the purposes of subsequent analysis, interventions were categorized after review of angiograms by an interventional cardiologist as either significant interventions or of uncertain significance (coil occlusion of tiny or small aortopulmonary collaterals or venovenous collaterals was considered to be of uncertain significance).

\section{Statistical Analysis}

Logistic regression was used to explore the relationship between dichotomous outcome variables (any complications, any significant intervention, need for transfusion, ICU admission) and preCATH patient characteristics and ECHO information. Similarly, linear regression was used for continuous outcome variables (hospital LOS, fluoroscopy time). Because the continuous outcome variables were not normally distributed, a log transformation was used. Evaluation of the associations among the outcome variables themselves was performed using Fisher's exact test for 2 dichotomous outcomes (eg, to assess the relationship between complications and significant interventions), the Wilcoxon rank sum test for 1 dichotomous and 1 continuous outcome, and the Spearman rank correlation coefficient for the 2 continuous outcomes.

\section{Results}

A total of 114 patients underwent pre-SCPA evaluation during the study period. Patient characteristics including ventricular type, prior operations, prior CATH history, and demographics and anthropometrics are listed in Table 1. ECHO and CATH results are shown in Tables 2-5. Results of pre-SCPA ECHO evaluation are listed in Table 2. Patients with incomplete ECHO evaluation were ascribed to unsedated study (11), failed sedation (4), poor acoustic windows (8), or simply incomplete study (12). Hemodynamic results from $\mathrm{CATH}$ were notable for median pulmonary arterial pressure of $17 \mathrm{~mm} \mathrm{Hg}$ (range 9 to 30), with median calculated pulmonary vascular resistance 2.3 Woods units $/ \mathrm{m}^{2}$ (range 0.4 to 11.6 ); other CATH findings are summarized in Table 3. Forty-one interventions were performed in 35 patients $(31 \%)$, summarized in Table 4. 
TABLE 1. Patient characteristics $(\mathbf{n}=114)^{*}$

\begin{tabular}{lc}
\hline Ventricular type & \\
Hypoplastic left heart syndrome & $41(36 \%)$ \\
Heterotaxy syndrome & $20(17 \%)$ \\
Single LV/NRGA & $18(16 \%)$ \\
Single LV/TGA & $14(12 \%)$ \\
Single right ventricle & $10(9 \%)$ \\
Other & $11(10 \%)$ \\
Prior operation & \\
None & $12(11 \%)$ \\
Norwood/Stage I & $54(47 \%)$ \\
Modified Blalock-Taussig shunt & $31(27 \%)$ \\
Main pulmonary artery band & $9(8 \%)$ \\
RVOT patch with modified BT shunt & $4(3.5 \%)$ \\
TAPVR repair, \pm modified BT shunt & $4(3.5 \%)$ \\
Prior catheterization & $35(31 \%)$ \\
Age at catheterization (months) & $5.5(1.1-160)$ \\
Weight (kg) & $6.0(3.2-50)$ \\
Weight for age centile (\%) & $20.6(0.2-99.3)$ \\
Weight for age z score (SD) & $-1.27(-4.68-1.70)$ \\
Height (cm) & $63(40.5-155.5)$ \\
Body surface area (m2) & $0.33(0.21-1.42)$ \\
Cutaneous saturation (\%) & $76(55-90)$ \\
Hemoglobin (g/dL) & $15.9(10-20.5)$ \\
\hline
\end{tabular}

*Values listed are number (\%) or median (range). LV, Left ventricle; NRGA, normally related great arteries; TGA, transposed great arteries; $R V O T$, right ventricular outflow tract; $B T$, Blalock-Taussig; TAPVR, totally anomalous pulmonary venous return.

Complications of CATH are listed in Table 5. Of the 114 patients, $28(25 \%)$ had at least 1 complication related to CATH. There were no deaths, no neurologic sequelae or strokes, no retroperitoneal bleeds, no surgical interventions for bleeding, and no wound or bloodstream infections related to CATH in this cohort of patients. Additional surgical procedures performed at the time of SCPA included PA plasty in 25 patients, atrial septectomy in 9 patients, and atrioventricular valve plasty in 5 patients.

\section{Interventions}

After review of relevant angiograms, interventions were categorized as either significant or of uncertain significance; the latter were limited to the coil occlusion of tiny or small aortopulmonary or venovenous collaterals. Of the 35 patients with any intervention, 27 patients had significant interventions.

In multivariable analysis, significant interventions were more common in patients with coarctation or distal arch obstruction by $\mathrm{ECHO}$ (odds ratio $[\mathrm{OR}]=3.6, P=.02$ ). The relationship between ventricular type and intervention approached but did not achieve statistical significance, with significant interventions more common in single RV patients $(50 \%$ versus those with other ventricular types $21 \%$, $P=.06)$.

Those with significant interventions had longer fluoroscopy times (median 54 minutes versus $40 \mathrm{~min}, P=.04$ ),
TABLE 2. Echocardiographic findings

\begin{tabular}{|c|c|c|}
\hline Finding evaluated & $\begin{array}{l}\text { Patients } \\
\text { evaluated }\end{array}$ & Details \\
\hline $\begin{array}{l}\text { Complete } \\
\text { echocardiogram }\end{array}$ & $79(69 \%)$ & See text \\
\hline \multirow{4}{*}{$\begin{array}{l}\text { Ventricular } \\
\text { function }\end{array}$} & $114(100 \%)$ & Good function-88 (77\%) \\
\hline & & Mild dysfunction-11 (10\%) \\
\hline & & Mod dysfunction-10 (9\%) \\
\hline & & Severe dysfunction-5 (4\%) \\
\hline \multirow{4}{*}{$\begin{array}{l}\text { Systemic AV } \\
\quad \text { valve } \\
\text { regurgitation }\end{array}$} & $113(99 \%)$ & No/trivial AVVR—66 (58\%) \\
\hline & & Mild AVVR-31 (28\%) \\
\hline & & Mod AVVR-14 (12\%) \\
\hline & & Severe AVVR-2 $(2 \%)$ \\
\hline Atrial septum & $106(93 \%)$ & Restrictive/intact-9 (8\%) \\
\hline $\begin{array}{c}\text { Proximal arch } \\
\text { obstruction }\end{array}$ & $104(91 \%)$ & Arch obstruction-2 (2\%) \\
\hline $\begin{array}{l}\text { Distal arch } \\
\text { obstruction }\end{array}$ & $92(81 \%)$ & Arch obstruction-17 (18\%) \\
\hline $\begin{array}{l}\text { Left pulmonary } \\
\text { artery }\end{array}$ & $83(73 \%)$ & $\geq$ Mild LPA stenosis-12 (14\%) \\
\hline $\begin{array}{l}\text { Right pulmonary } \\
\text { artery }\end{array}$ & $86(75 \%)$ & $\geq$ Mild RPA stenosis-14 (16\%) \\
\hline $\begin{array}{l}\text { Both pulmonary } \\
\text { arteries }\end{array}$ & $83(73 \%)$ & $\geq$ Mild PA stenosis-24 (29\%) \\
\hline $\begin{array}{l}\text { Presence } \\
\quad \text { bilateral SVC }\end{array}$ & $113(99 \%)$ & Bilateral SVC-25 (22\%) \\
\hline $\begin{array}{l}\text { Pulmonary } \\
\text { venous } \\
\text { obstructio }\end{array}$ & $113(99 \%)$ & Mild single PV obst.-1 (1\%) \\
\hline
\end{tabular}

Unilateral PV atresia-2 $(2 \%)$

Stenosis PV confluence-1 $1 \%)$

Severe stenosis mult PVs-2 $(2 \%)$

Mod, Moderate; $A V$, atrioventricular; $A V V R$, atrioventricular valve regurgitation; $P A$, pulmonary artery; $L P A$, left pulmonary artery; $R P A$, right pulmonary artery; $S V C$, superior vena cava; $P V$, pulmonary vein; obst, obstruction; mult, multiple.

more frequent transfusions ( $48 \%$ vs $16 \%, P=.001$ ), ICU admissions ( $33 \%$ vs $11 \%, P=.02$ ), complications ( $41 \%$ vs $20 \%, P=.04)$, and longer median hospital LOS (2 days vs 1 day, $P=0.005)$. Patients with significant interventions or new findings at catheterization had lower median weight for age centile (4.1 vs $14.2, P=.003)$ and lower median weight z-score $(-1.7$ vs $-1.1, P=.003)$, but no significant differences in height for age centile or $z$-score, weight for height, saturation, or hemoglobin level.

\section{Complications}

As noted above, 28 of the 114 patients (25\%) had at least 1 complication. In multivariable analysis of pre-CATH variables, patients who had any PA stenosis noted on ECHO were more likely to have a complication $(\mathrm{OR}=2.9, P=$ .01). In addition, patients without evidence of aortic ob- 
TABLE 3. Catheterization findings

\begin{tabular}{|c|c|c|}
\hline Finding evaluated & $\begin{array}{l}\text { Patients } \\
\text { evaluated }\end{array}$ & Details \\
\hline Atrial septum & $114(100 \%)$ & Restrictive/intact-8 (7\%) \\
\hline $\begin{array}{c}\text { Proximal arch } \\
\text { obstruction }\end{array}$ & $114(100 \%)$ & Arch Obstruction-4 (3.5\%) \\
\hline $\begin{array}{l}\text { Distal arch } \\
\text { obstruction }\end{array}$ & $114(100 \%)$ & Arch Obstruction-14 (12\%) \\
\hline \multirow{2}{*}{$\begin{array}{l}\text { Left pulmonary } \\
\text { artery }\end{array}$} & $114(100 \%)$ & Mild LPA stenosis-15 (13\%) \\
\hline & & $\begin{array}{l}\text { Moderate LPA stenosis-4 }(4 \%) \\
\text { Severe LPA stenosis-2 }(2 \%) \\
\text { No flow to LPA-1 }(1 \%)\end{array}$ \\
\hline \multirow{3}{*}{$\begin{array}{l}\text { Right pulmonary } \\
\text { artery }\end{array}$} & $114(100 \%)$ & Mild RPA stenosis-16 (14\%) \\
\hline & & Moderate RPA stenosis-5 (4\%) \\
\hline & & Severe RPA stenosis-1 (1\%) \\
\hline $\begin{array}{l}\text { Both pulmonary } \\
\text { arteries }\end{array}$ & $114(100 \%)$ & $\geq$ Mild PA stenosis-39 $(34 \%)$ \\
\hline $\begin{array}{l}\text { Presence bilateral } \\
\text { SVC }\end{array}$ & $108(95 \%)$ & Bilateral SVC-26 (24\%) \\
\hline $\begin{array}{l}\text { Pulmonary venous } \\
\text { obstruction }\end{array}$ & $114(100 \%)$ & Obstruction/atresia-6 $(5 \%)$ \\
\hline $\begin{array}{l}\text { Venovenous } \\
\text { collaterals }\end{array}$ & $108(95 \%)$ & Tiny/small collaterals-6 $(5 \%)$ \\
\hline $\begin{array}{l}\text { Aortopulmonary } \\
\text { collaterals }\end{array}$ & $112(99 \%)$ & Small collaterals-10 (9\%) \\
\hline
\end{tabular}

$P A$, Pulmonary artery; $L P A$, left pulmonary artery; $R P A$, right pulmonary artery; $S V C$, superior vena cava; $P V$, pulmonary vein.

struction (proximal or distal) by ECHO were less likely to have a complication $(\mathrm{OR}=0.22, P=.001)$.

\section{Fluoroscopy Time}

Median fluoroscopy time for this group of patients was 44 minutes, with a range of 13 to 220 minutes. In multivariable analysis, prior operation was the only significant predictor of fluoroscopy time, with patients with prior Stage I Norwood procedure having shorter fluoroscopy times than those with other procedures or no prior operation $(P=.001)$.

\section{Transfusions}

Of the 114 patients, 27 (24\%) received a blood transfusion. In multivariable analysis, a higher cutaneous saturation was the best predictor of transfusion (OR $=2.0$ for each $10 \%$ increase in saturation, $P=.06$ ). However, no relationship was observed with baseline hemoglobin level and transfusion.

\section{ICU Admissions}

Of the 114 patients, $18(17 \%)$ were admitted to the cardiac ICU following catheterization. However, 2 of the 18 patients were ICU inpatients prior to catheterization (1 ventilator-dependent and the other intravenous inotrope-dependent). In multivariable analysis, patients with severe
TABLE 4. CATH Interventions

\begin{tabular}{ll}
\hline Type & $\begin{array}{c}\text { Number of } \\
\text { patients }\end{array}$ \\
\hline Any intervention & $35(31 \%)$ \\
Significant interventions* & 27 \\
Balloon dilation aortic obstruction & 10 \\
Coil venovenous collaterals & 10 \\
Coil aortopulmonary collaterals & 7 \\
Hemodynamic testing (balloon occlusion, $\left.\mathrm{NO} / \mathrm{O}_{2}\right)$ & 6 \\
Pulmonary artery dilation & 3 \\
Pulmonary vein dilation & 2 \\
ASD creation/balloon dilation & 2 \\
Balloon dilation pulmonary valve & 1 \\
\hline
\end{tabular}

*See text for definition of nonsignificant interventions. $N O$, nitric oxide, $\mathrm{O}_{2}$, oxygen; $A S D$, atrial septal defect.

\section{TABLE 5. CATH Complications}

\begin{tabular}{lc}
\hline Type & Number of patients \\
\hline Any complication & $28(25 \%)$ \\
Arrhythmia (sustained or requiring treatment) & 7 \\
Acidosis (arterial $\mathrm{pH}<7.25)$ & 15 \\
Nonelective intubation & 8 \\
Initiation IV inotropes & 3 \\
CPR/chest compressions & 2 \\
Other complications & 2 \\
$\quad$ Severe hypertension requiring treatment & 2 \\
Loss of femoral arterial pulse & 1 \\
Clot in modified BT shunt & 1 \\
Retained wire fragment & 1 \\
Large pelvic hematoma & 1 \\
Emergent transfer to OR (cyanosis) &
\end{tabular}

$I V$, Intravenous; $C P R$, cardiopulmonary resuscitation; $B T$, Blalock-Taussig; $O R$, operating room.

ventricular dysfunction by ECHO were more likely to have an ICU admission $(\mathrm{OR}=12.5, P=.01)$. In particular, $60 \%$ of patients with severe ventricular dysfunction required ICU admission. Patients with prior Stage I Norwood procedure were less likely to require ICU admission $(\mathrm{OR}=0.27, P=$ $.03)$.

\section{Length of Hospital Stay}

Median LOS was 1 day, with range from 0 to 22 days. In multivariable analysis, patients with severe ventricular dysfunction by ECHO had longer hospital LOS (median 6 days for those with severe ventricular dysfunction, $P<.001$ ).

\section{Patients Excluded from SCPA Operation}

During the 3.5-year period of the study, 3 patients who underwent pre-SCPA evaluation were excluded from SCPA. All excluded patients had heterotaxy syndrome, 2 had severe stenoses of multiple individual pulmonary veins, and the third patient had severe bilateral PA hypoplasia. All 
3 patients were correctly identified by ECHO as having significant issues requiring $\mathrm{CATH}$.

\section{Comparison of ECHO and CATH data}

Patients were divided into subgroups based on the results of the pre-SPCA ECHO evaluation according to the completeness of ECHO study and suspected issues requiring CATH evaluation. Patients were also divided into 1 of 3 categories according to the results of the pre-SCPA CATH: those with no intervention or new findings, those with interventions of uncertain significance, and those with significant interventions or new findings. Figure 1 presents the results of this analysis. Of the 51 patients who had a complete ECHO and in whom there were no suspected issues requiring CATH evaluation, only 2 patients had the unsuspected finding of pulmonary artery stenosis and underwent surgical arterioplasty at the time of SCPA, and no patients had a significant intervention during the CATH.

Procedure-related outcomes in this subgroup of 51 patients included a mean fluoroscopy time of 44 minutes, 5 transfusions (10\%), 7 admissions to the ICU (14\%), and 10 CATH-related complications (20\%).

A similar analysis for patients with hypoplastic left heart syndrome is presented in Figure 2. Although fewer of these patients had a complete ECHO (25 of 41 patients, $61 \%$ ), of the 14 patients in whom no issues requiring $\mathrm{CATH}$ were identified by ECHO, no patients had a significant intervention at CATH.

\section{Discussion}

Over the past 2 decades, with the advent of 2-dimensional and Doppler echocardiography and refinements in ultrasound technology, the role of hemodynamic CATH in the routine preoperative evaluation of patients with congenital heart disease has been steadily decreasing. In 1984, Freed and colleagues ${ }^{2}$ demonstrated that routine CATH was unnecessary prior to repair of secundum and sinus venosus atrial septal defect; 4 years later, Lipshultz and colleagues ${ }^{3}$ showed the same was true for ostium primum atrial septal defect. A growing body of literature testifies to the success of surgery following noninvasive evaluation alone for selected cardiac lesions. ${ }^{4-7}$

However, for patients requiring single ventricle palliation, in particular SCPA and Fontan operation, routine preoperative CATH is still standard of care in many institutions, including our own. In addition to providing an assessment of pulmonary arterial and venous architecture and pulmonary vascular resistance, CATH assists in evaluating systemic outflow tract and arch obstruction. Moreover, catheter-based interventions such as balloon dilation of aortic arch obstruction have proven useful adjuncts to the surgical care of such patients.
In this retrospective review we examined the evaluation of pre-SCPA candidates to characterize the quality of the information obtained by ECHO and $\mathrm{CATH}$, the interventions performed at $\mathrm{CATH}$, and any associated morbidity. Finally, we attempted to define patients who are unlikely to benefit from CATH in terms of either intervention or change in the planned surgical procedure.

\section{Preoperative ECHO Adequacy}

Although our definition of complete ECHO assessment was fairly demanding, this was performed in nearly $70 \%$ of pre-SCPA candidates. Due to the expense, inconvenience, and risk of sedation, incomplete preoperative echocardiographic assessment is often accepted based on the knowledge that a catheterization is planned prior to surgery. Because study limitations in the remaining patients were frequently ascribed to either unsedated or failed sedation patients, it is likely that additional patients could have had a complete evaluation with better planning, preparation, and the assistance of the anesthesia staff with difficult sedations. Only 8 patients had poor $\mathrm{ECHO}$ windows cited as a study limitation, and for these patients, clearly other methods of preoperative evaluation would have been necessary.

For those with inadequate ECHOs, evaluation of the aortic arch and the branch pulmonary arteries were the portions most often missed and presumably the most difficult to image. The aortic arch was assessed in $81 \%$ of patients, and both branch pulmonary arteries in $73 \%$. In this diverse group of patients, ECHO had a sensitivity of $100 \%$ for aortic arch obstruction; however, it falsely predicted coarctation not confirmed at CATH in three patients (all hypoplastic left heart syndrome [HLHS] patients after Stage I Norwood). This result differs somewhat from prior published reports suggesting ECHO is specific but of limited sensitivity for aortic arch obstruction for patients after Stage I Norwood procedure. ${ }^{8}$ However, our sample size of HLHS patients was smaller and it may be reasonable to assume that HLHS patients present difficulties in arch evaluation for $\mathrm{ECHO}$ and may require other methods of preoperative arch evaluation.

Branch PA assessment was successful in $73 \%$ of patients on the pre-SCPA ECHO. For those patients in whom the branch PAs were successfully evaluated by ECHO, agreement with CATH assessment occurred $82 \%$ of the time. In the remaining $18 \%$, lack of agreement was due to a disparity of 1 grade; for example, moderate stenosis by ECHO and mild by CATH. In only 2 cases did ECHO fail to detect PA stenosis in patients who later had PA plasty at the time of SCPA. Both of these patients had undergone prior Stage I Norwood procedure, indicating again that this group of patients may benefit from further preoperative evaluation. 


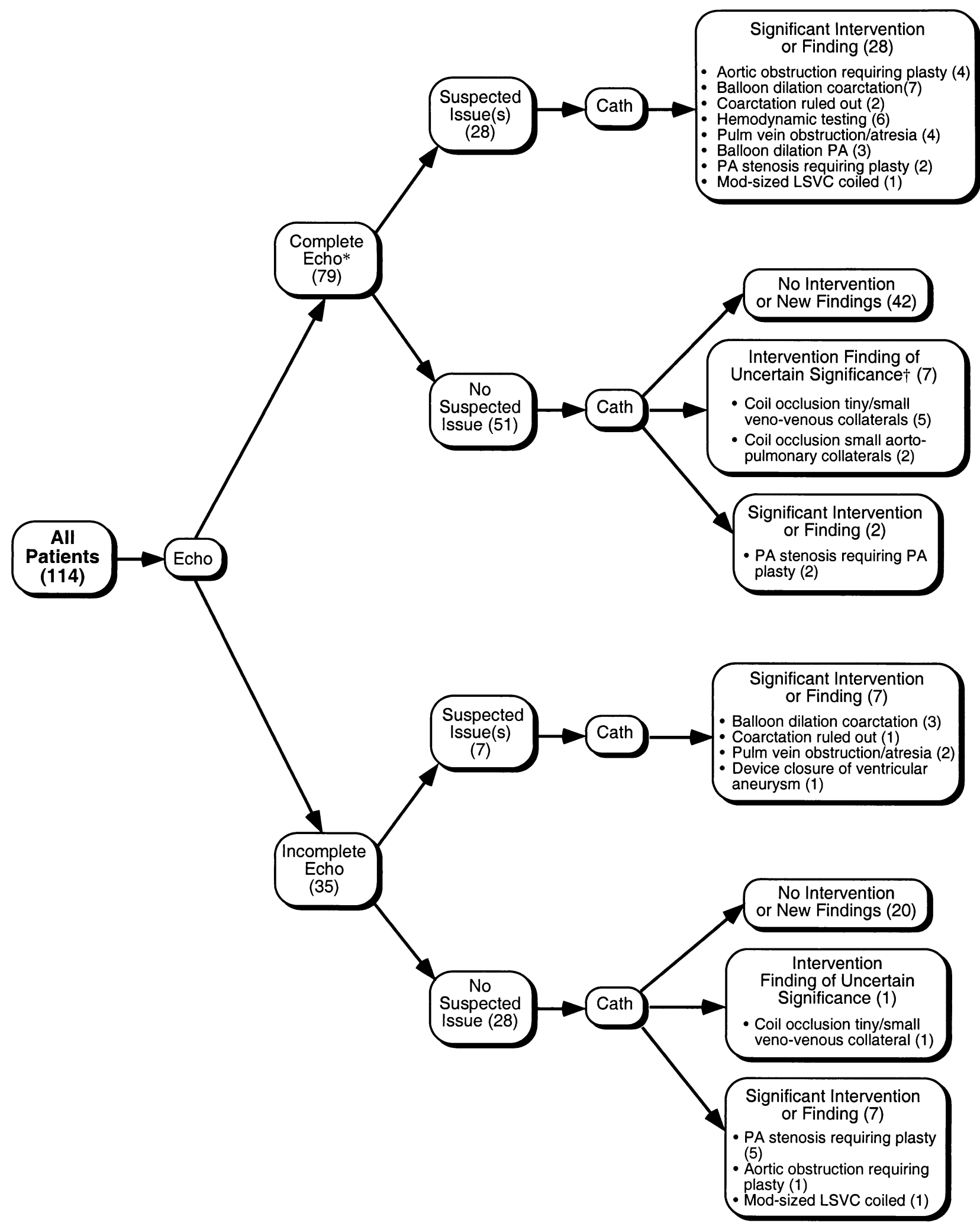

Figure 1. Echocardiogram and catheterization data by subgroup analysis. *For definition of complete ECHO, see "Methods." †Significant interventions defined in "Methods." PA, Pulmonary artery; pulm, pulmonary; mod, moderate; $L S V C$, left superior vena cava. 


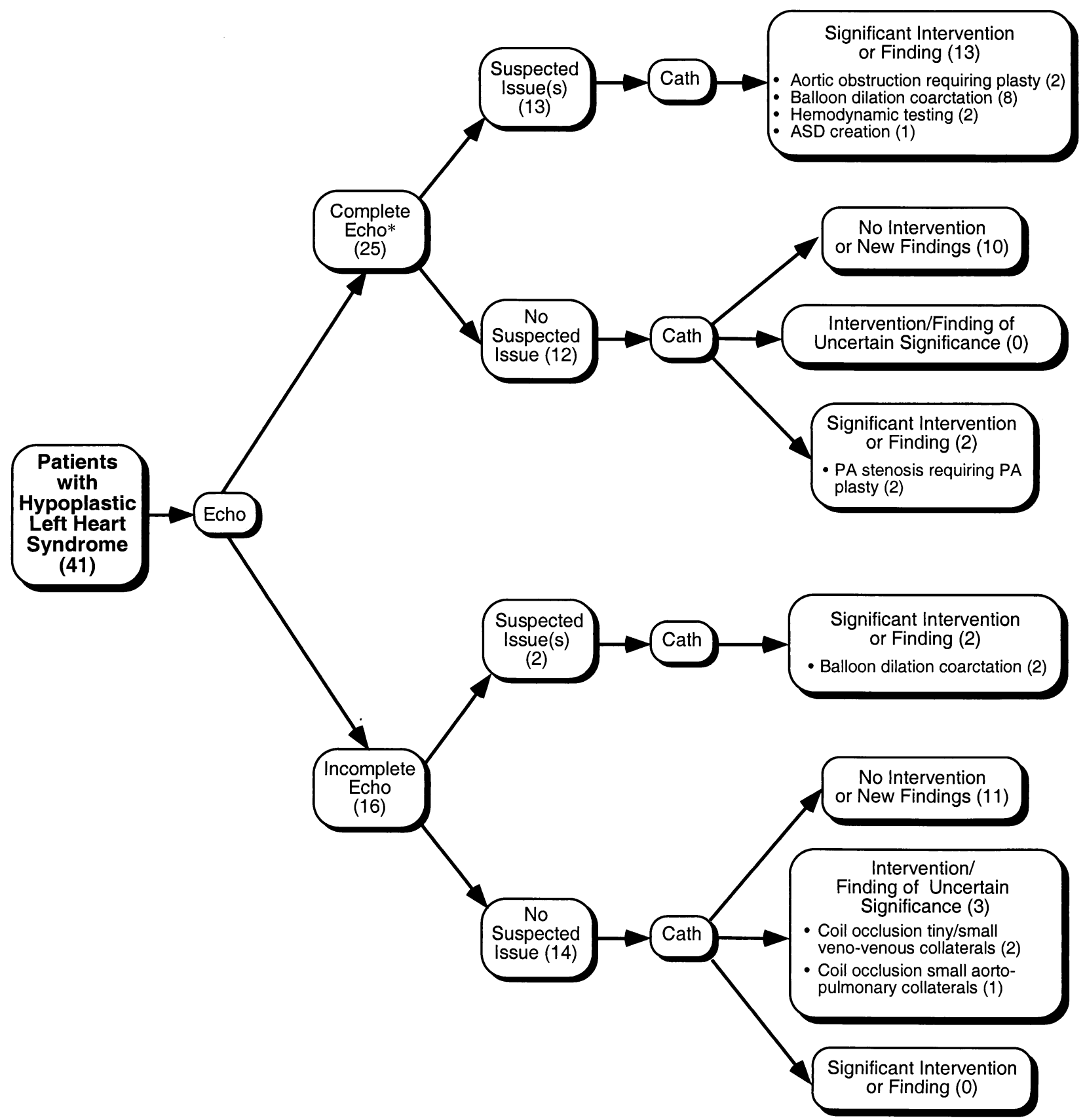

Figure 2. Echocardiogram and catheterization subgroup analysis for patients with hypoplastic left heart syndrome. *For definition of complete ECHO, see "Methods." †Significant interventions defined in "Methods." PA, Pulmonary artery; pulm, pulmonary; mod, moderate; $L S V C$, left superior vena cava.

\section{Post-CATH Outcomes and Complications}

For patients who do not have interventions performed during the pre-SCPA CATH, improved preoperative diagnosis may avoid the need for CATH and therefore catheterization-related complications. For example, although few published data exist on radiation exposure in routine pediatric cardiac $\mathrm{CATH},{ }^{9,10}$ and no data exist on the pre-SCPA CATH in particular. The median fluoroscopy time was 44 minutes in the two thirds of patients who did not have intervention at $\mathrm{CATH}$, a significant exposure in a population likely to undergo multiple CATHs.

In addition, transfusions were common, occurring in $24 \%$ of patients. Although transfusions among patients who 
had interventions performed were frequent, nearly half of the transfusions (12 of 27) occurred in those who had no intervention performed. We are unaware of any published series documenting the rate of transfusion after CATH in a comparable group of patients. Although a relationship of borderline significance was observed with higher cutaneous saturation and transfusion, which suggested that those with lower hemoglobin values were more likely to be transfused, baseline hemoglobin and transfusion proved to have no significant relationship in this group of patients.

Eighteen patients (17\%) required cardiac ICU admission with an increased risk in those with severe ventricular dysfunction (odds ratio $12.5, P=.01$ ). Median LOS following CATH was 1 day (range 0 to 22) and was significantly longer for those with severe ventricular dysfunction $(P<.001)$. Clearly, patients with severe ventricular dysfunction are high-risk CATH patients, and noninvasive methods of evaluation may be even more desirable for this subgroup, especially given that half of the patients in this subgroup had no intervention at CATH.

Complications occurred in 25\% of pre-SCPA candidates, although most were transient, and there was no associated mortality. Several series on pediatric CATH have been published in the last 2 decades, with complication rates ranging from $1.5 \%$ to $25 \%{ }^{11-16}$ Young age at $\mathrm{CATH}$, low body weight, and interventional procedures have been established as risk factors for complications, ${ }^{17-19}$ all of which were common in this group of patients, with a mean age of 5.5 months and a mean weight of $6.0 \mathrm{~kg}$. However, half of the patients who had complications (15 of 31 patients) did not have an intervention performed at CATH.

\section{Significance of CATH Interventions}

Although the importance of performing an intervention during the pre-SCPA CATH is at times uncertain, it nevertheless influences the retrospective assessment as to whether the CATH was necessary. Overall, interventions were performed in $31 \%$ of our patients, with the most common intervention being balloon dilation of the aortic arch (10 patients). This number reflects the high proportion of patients after Stage I Norwood procedure in our study, in whom a documented propensity for distal arch obstruction has been described ${ }^{20}$ and in whom balloon dilation of the arch was most commonly performed. Other interventions that we classified as important in this analysis included coil occlusion of moderate or large aortopulmonary or venovenous collaterals, as well as hemodynamic testing with oxygen or nitric oxide to assess pulmonary vascular reactivity. In contrast, we classified the coil occlusion of small venovenous or aortopulmonary collaterals as "interventions of uncertain significance" that may have no demonstrable benefit to the patient and would not solely constitute a clear justification for the procedure. Although frequently these interventions were accompanied by other "significant" interventions, for some patients these were the only intervention performed.

Venovenous collaterals after SCPA can be a cause of cyanosis, with the elevation in superior vena caval pressures presumably leading to the enlargement of existing venovenous connections. Magee and colleagues ${ }^{21}$ found that nearly a third of their patients developed venous collaterals after SCPA, and development of such vessels was associated with higher mean gradient between superior vena cava and right atrium. However, no study has examined the impact of coil occlusion of such vessels on morbidity after SCPA, short or long term; and furthermore, tiny or small venovenous collaterals that become larger after SCPA could ostensibly be effectively coiled prior to Fontan operation at lower risk due to patient growth.

Aortopulmonary collaterals have long been suspected to contribute to postoperative morbidity, presumably due to the excess volume load incurred on the single ventricle circulation. However, to date no controlled prospective studies have addressed this issue. ${ }^{22}$ Indeed, several recent retrospective studies have documented that the presence of aortopulmonary collaterals in Fontan patients has had no impact on postoperative hemodynamics, duration of effusions, duration of tube thoracostomy, or resource utilization after the Fontan procedure. ${ }^{23,24}$ Therefore, based on the available data, the coil occlusion of small aortopulmonary collaterals is not known to have an effect on postoperative outcomes and may be considered of questionable value.

\section{Identification of Patients Unlikely to Benefit From Catheterization}

For assessments of AV valve regurgitation, ventricular function, and the status of the atrial septum, ECHO is generally accepted as an excellent modality alone in guiding surgical decision making; this has been demonstrated in the literature for many forms of congenital heart disease. ${ }^{2-6}$ In this series, hemodynamic and angiographic CATH assessments of ventricular function, for example, were frequently not performed (40\%); the same is true for AV valve regurgitation. Five patients underwent AV valve plasty at time of SCPA, each of whom had either moderate or severe AV valve regurgitation by ECHO. In this series, CATH did not provide new information on either ventricular function or AV valve regurgitation. The atrial septum was visualized well in nearly all patients by ECHO, and when seen, had a perfect correlation with catheterization data. In 2 cases, the atrial septum was dilated, but in both cases this was a temporizing measure prior to surgical atrial septal defect creation at time of SCPA, and the necessity of this as an intervention itself may be questionable, although in this review this was included as a significant intervention. Furthermore, in all 9 cases where atrial septectomy was performed at the time of SCPA, ECHO correctly identified the 
atrial septum as restrictive or intact. Pulmonary artery stenoses were accurately documented by ECHO prior to CATH in nearly all patients; in the 25 patients who had PA plasty performed at the time of SCPA, 23 of these had mild or greater branch PA stenoses identified by ECHO. These stenoses were rarely intervened on at catheterization (3 patients), and thus in this series were not a reason for catheterization when the pulmonary arteries can be imaged noninvasively.

When patients were categorized into those with a complete $\mathrm{ECHO}$ and no suspected issues requiring CATH (51 patients, or $48 \%$ of our study group), only 2 patients had significant unsuspected findings (both Stage I Norwood patients with pulmonary artery stenosis who had pulmonary arterioplasty at the time of SCPA) and no patients subsequently had a significant intervention at CATH. Forty-two patients had no intervention, and 7 had interventions of uncertain significance as discussed previously. Furthermore, this group of patients was not free from morbidity; in addition to mean fluoroscopy times of 44 minutes, 5 of the 27 transfusions, 7 of 18 ICU admissions, and 10 of the 31 complications occurred in this subgroup of patients. It is difficult to ascertain whether the identification of unsuspected PA stenosis in 2 of 51 patients was clinically important to the achievement of a successful postoperative outcome; however, the diagnostic yield of new findings in this group seems low, especially in light of the high rate of CATH-related morbidity and the potential ability to establish such a diagnosis either intraoperatively or by other noninvasive tests such as cardiac MRI.

Importantly, of the 3 patients excluded from SCPA based upon the pre-SCPA evaluation, all were correctly identified on $\mathrm{ECHO}$ as having important risk factors requiring $\mathrm{CATH}$ ( 2 patients with pulmonary vein stenosis and 1 patient with severely hypoplastic pulmonary arteries). The remaining 111 patients underwent successful SCPA and survived to hospital discharge.

\section{Study Limitations}

As a retrospective review of patients referred for pre-SCPA evaluation, this study is prone to all the biases inherent in such studies. In particular, it is quite difficult to discern retrospectively the precise clinical indications for some outcomes, such as transfusion or ICU admission; as clinical decisions, it is possible that some of these may reflect forms of institutional bias. In addition, outcomes such as fluoroscopy time may be affected by the status of our institution as a teaching hospital, and perhaps not generalizable to other non-teaching venues.

Furthermore, as this study did not examine postoperative outcomes beyond survival to hospital discharge, no conclusions regarding CATH data and postoperative management and other outcomes (such as duration of postoperative ICU stay) are possible, and knowledge of CATH data may have improved such outcomes for these patients. In addition, due to the retrospective nature of this study, how the surgical plan may have changed prior to and following ECHO and CATH can only be inferred.

\section{Implications}

Complete ECHO evaluation prior to SCPA can successfully identify a subgroup of patients in whom no issues are identified requiring CATH evaluation or intervention; CATH rarely benefits these patients and is associated with significant morbidity. Two patients after Stage I Norwood who had pulmonary arterioplasty at time of surgery were missed in this group of patients by ECHO evaluation alone, suggesting that pre-SCPA CATH may be indicated in all patients with this diagnosis. Alternatively, magnetic resonance imaging may represent an excellent noninvasive alternative to routine $\mathrm{CATH}$ and would provide anatomic information on branch and distal pulmonary arteries and pulmonary veins, as well as proximal and distal arch anatomy. ${ }^{25}$

Interventions were often performed as part of pre-SCPA $\mathrm{CATH}$, but transient complications, transfusion, ICU admission, and prolonged hospital LOS were common in this high-risk group of patients regardless of whether or not an intervention was performed. We conclude that patients who have evidence of aortic arch or pulmonary venous obstruction, significant aortopulmonary or venovenous collaterals, or for whom hemodynamic testing is warranted should continue to be catheterized, as well as those with inadequate noninvasive imaging of the aortic arch, pulmonary arteries, pulmonary veins, atrial septum, or AV valve regurgitation. For selected patients in whom no issues requiring CATH are identified by ECHO, routine CATH rarely results in new information or intervention, and these patients may be more safely evaluated with noninvasive techniques prior to SCPA.

\section{References}

1. Gentles TL, Mayer JE, Gauvreau K, et al. Fontan operation in five hundred consecutive patients: factors influencing early and late outcome. J Thorac Cardiovasc Surg. 1997;114:376-91.

2. Freed MD, Nadas AS, Norwood WI, Castenada AR. Is routine preoperative cardiac catheterization necessary before repair of secundum and sinus venosus atrial septal defects? J Am Coll Cardiol. 1984;4: 333-6.

3. Lipshultz SE, Sanders SP, Mayer JE, Colan SD, Lock JE. Are routine preoperative cardiac catheterization and angiography necessary before repair of ostium primum atrial septal defect? J Am Coll Cardiol. 1988;11:373-8.

4. Huhta JC, Glasow P, Murphy DJ, et al. Surgery without catheterization for congenital heart defects: management of 100 patients. J Am Coll Cardiol. 1987;9:823-9.

5. Pfammatter JP, Berdat PA, Carrel TP, Stocker FP. Pediatric open heart operations without diagnostic cardiac catheterization. Ann Thorac Surg. 1999;68:532-6.

6. Tworetzky W, McElhinney DB, Brook MM, Reddy VM, Hanley FL, Silverman NH. Echocardiographic diagnosis alone for the complete 
repair of major congenital heart defects. J Am Coll Cardiol. 1999;33: 228-33.

7. Pfammatter JP, Berdat P, Hammerli M, Carrel T. Pediatric cardiac surgery after exclusively echocardiography-based diagnostic work-up. Int J Cardiol. 2000;74:185-90.

8. Fraisse A, Colan SD, Jonas RA, Gauvreau K, Geva T. Accuracy of echocardiography for detection of aortic arch obstruction after stage I Norwood procedure. Am Heart J. 1998;135:230-6.

9. Waldman JD, Rummerfield PS, Gilpin EA, Kirkpatrick SE. Radiation exposure to the child during cardiac catheterization. Circulation. 1981; 64:158-63

10. Schueler BA, Julsrud PR, Gray JE, Stears JG, Wu KY. Radiation exposure and efficacy of exposure-reduction techniques during cardiac catheterization in children. AJR. 1994;162:173-7.

11. Stanger P, Heymann MA, Tarnoff H, Joffman JI, Rudolph AM. Complications of cardiac catheterization of neonates, infants, and children. Circulation. 1974;50:595-608.

12. Cohn HE, Freed MD, Hellenbrand WF, Fyler DC. Complications and mortality associated with cardiac catheterization in infants under one year: a prospective study. Pediatr Cardiol. 1985;6:123-31.

13. Fellows KE, Wolfgang R, Keane JF, Lock JE. Acute complications of catheter therapy for congenital heart disease. Am J Cardiol. 1987;60: 679-83.

14. Booth P, Redington AN, Shinebourne EA, Rigby ML. Early complications of interventional balloon catheterization in infants and children. Br Heart J. 1991;65:109-12.

15. Cassidy SC, Schmidt KG, Van Hare GF, Stanger P, Teitel DF. Complications of pediatric cardiac catheterization: a three year study. $J \mathrm{Am}$ Coll Cardiol. 1992;19:1285-93.

16. Zeevi B, Berant M, Fogelman R, Galit BM, Blieden LC. Acute complications in the current era of therapeutic cardiac catheterization for congenital heart disease. Cardiol Young. 1999;9:266-72.

17. Pophal SG, Sigfusson G, Booth KL, et al. Complications of endomyocardial biopsy in children. J Am Coll Cardiol. 1999;34:2105-10.

18. Rhodes JF, Asnes JD, Blaufox AD, Sommer RJ. Impact of low body weight on frequency of pediatric cardiac catheterization complications. Am J Cardiol. 2000;86:1275-8.

19. Vitiello R, McCrindle BW, Nykanen D, Freedom RM, Benson LN. Complications associated with pediatric cardiac catheterization. J Am Coll Cardiol. 1998;32:1433-40.

20. Tworetzky W, McElhinney DB, Burch GH, Teitel DF, Moore P. Balloon arterioplasty of recurrent coarctation after the modified Norwood procedure in infants. Catheter Cardiovasc Interv. 2000;50:54-8.

21. Magee AG, McCrindle BW, Mawson J, Benson LN, Williams WG, Freedom RM. Systemic venous collateral development after the bidirectional cavopulmonary anastamosis. Prevalence and predictors. J Am Coll Cardiol. 1998;32:502-8.

22. Triedman JK, Bridges ND, Mayer JE Jr, Lock JE. Prevalence and risk factors for aortopulmonary collateral vessels after Fontan and bidirectional Glenn procedures. J Am Coll Cardiol. 1993;22:207-15.

23. McElhinney DB, Reddy VM, Tworetzky W, Petrossian E, Hanley FL, Moore P. Incidence and implications of systemic to pulmonary collaterals after bi-directional cavopulmonary anastamosis. Ann Thorac Surg. 2000;69:1222-8.

24. Bradley SM, McCall MM, Sistino JJ, Radtke WA. Aortopulmonary collateral flow in the Fontan patient: does it matter? Ann Thorac Surg. 2001;72:408-15.

25. Rezavi R, Miquel M, Summers P, Goodey J, Baker E. Gadolinium enhanced three-dimensional magnetic resonance angiography of patients with Glenn cavopulmonary shunts or Fontan operations (abstract). Society for Cardiovasc Magnetic Resonance 2001. 